\title{
Structural Optimization Design of Large Wind Turbine Blade considering Aeroelastic Effect
}

\author{
Yuqiao Zheng, ${ }^{1,2}$ Yongyong Cao,, ${ }^{1,2}$ Chengcheng Zhang, ${ }^{1,2}$ and Zhe He \\ ${ }^{1}$ Key Laboratory of Digital Manufacturing Technology and Application, The Ministry of Education, Lanzhou University of Technology, \\ Lanzhou 730050, China \\ ${ }^{2}$ College of Mechano-Electronic Engineering, Lanzhou University of Technology, Lanzhou 730050, China
}

Correspondence should be addressed to Yuqiao Zheng; zhengyuqiaolut@163.com

Received 27 July 2017; Revised 2 September 2017; Accepted 6 September 2017; Published 10 October 2017

Academic Editor: Chanho Jung

Copyright (C) 2017 Yuqiao Zheng et al. This is an open access article distributed under the Creative Commons Attribution License, which permits unrestricted use, distribution, and reproduction in any medium, provided the original work is properly cited.

\begin{abstract}
This paper presents a structural optimization design of the realistic large scale wind turbine blade. The mathematical simulations have been compared with experimental data found in the literature. All complicated loads were applied on the blade when it was working, which impacts directly on mixed vibration of the wind rotor, tower, and other components, and this vibration can dramatically affect the service life and performance of wind turbine. The optimized mathematical model of the blade was established in the interaction between aerodynamic and structural conditions. The modal results show that the first six modes are flapwise dominant. Meanwhile, the mechanism relationship was investigated between the blade tip deformation and the load distribution. Finally, resonance cannot occur in the optimized blade, as compared to the natural frequency of the blade. It verified that the optimized model is more appropriate to describe the structure. Additionally, it provided a reference for the structural design of a large wind turbine blade.
\end{abstract}

\section{Background and Motivation}

As a key wind turbine component, the blade is a determining factor for energy harvesting efficiency and a main source of complicated and extreme loads. Aeroelasticity is a key issue in the continuing development of wind turbines towards large, flexible, highly optimized machines. In the design optimization process, multiple objectives (maximum annual energy production, minimum cost of energy, minimum mass, minimum extreme load, and minimum noise) are usually included and may be contradictory with each other. With the wind turbine design development in the super large scale, extralong blades catching the wind are an urgent need. However, flutter occurs in coupled rigid and flexible multibody systems. On account of the coupling effect conditions of aerodynamic forces, elastic forces, and inertial forces, coupled with the wind turbine often running in the stall condition, the blade will easily undergo deformation and flutter for the large wind turbine. Consequently, studying the deformation and vibration of the blade under fluid structure interaction is of great significance to the safe operation of large wind turbines.

Recently, many scholars have studied the structural dynamics of wind turbine blades in the aerodynamic and structural coupling conditions. For instance, Zheng et al. [1] studied the optimization design of blade by using genetic algorithm under the aerodynamic and structural coupling condition. Liu and Ren [2] investigated vibration and aeroelastic stability of slender composite beams with thin-walled closed cross sections based on the extended Galerkin method. Twisty and flapwise vibration of rotating beams featuring composite material thin-walled was studied with a number of factors. The modal under fluid structure interaction was calculated and analyzed through the establishment of a full size fluid structure coupling model by $\mathrm{Hu}$ et al. [3]. Theoretical analysis and numerical calculation modes of the blade in the different rotation speeds and material paving methods were carried out by Yin et al. [4]. Cárdenas et al. [5] presented a numerical validation of a thin-walled beam finite element model of a realistic wind turbine blade. 


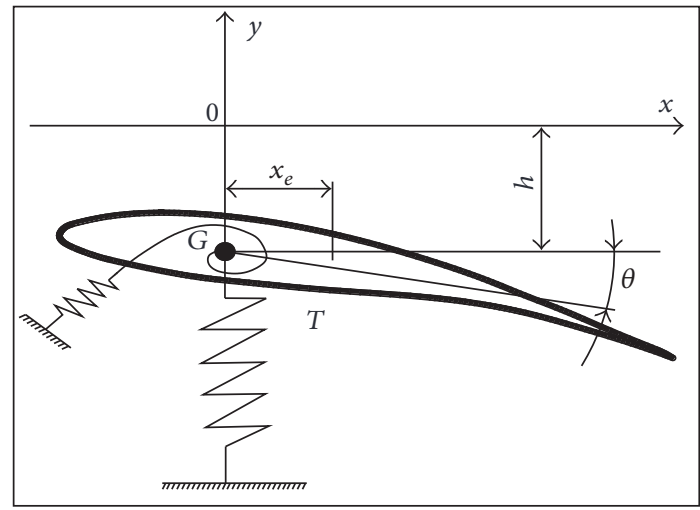

FIgURE 1: Simplified dynamic model of the blade.

Harte et al. [6] established the coupling model of the wind turbine; then the modal was analyzed under different loads. The modal of composite blades was analyzed in the case of the fluid structure interaction by Kang et al. [7]. Cortínez and Piovan [8] developed a theoretical model for the dynamic analysis of composite thin-walled beams with open or closed cross sections. Shokrieh and Rafiee [9] researched on the static analysis with a full 3D finite element method (FEM) and the critical zone where fatigue failure begins was observed. Malcolm and Laird [10] utilized shell element to extract the equivalent beam properties and generate the complete aeroelastic model of the blade.

In this work, the theoretical basis of aerodynamics was adopted. Meanwhile, taking the aerodynamic and structural coupling effect conditions into consideration, the mathematical model was established by taking the minimal mass of the blade as the optimization objective, the interaction mechanism between the blade tip deformation and load distribution was studied by using modal analysis. At the same time, it was illustrated that the establishment mathematical model is reasonable, and it also can improve the blade dynamic performance.

\section{Problem Statement}

The mathematical model is implemented in this work for the fluid dynamics optimization design of a wind turbine based on the differential equation motion. In the aerodynamic and structure coupling effect, airflow change was used as the excitation, and the blade deformation was used as the response. Studying on the dynamic design of the wind turbine blade can be described by Spring-Damping-Mass system. The simplified dynamic model of the cross section of a blade for unit length is shown in Figure 1.

$G$ is the center of the blade mass, $T$ is torsional center, $x_{e}$ is a distance from the center of mass to the torsional center, $h$ is the mean displacement of the centroid of the blade, and $\theta$ is the angular displacement around the center of mass.

The kinetic energy of unit blade vibration is given as

$$
T=\frac{1}{2} m \dot{h}^{2}+\frac{1}{2} J \dot{\theta}^{2}
$$

Potential energy of the system can be obtained by the following equation:

$$
U=\frac{1}{2} k_{h}\left(h-\theta x_{e}\right)^{2}+\frac{1}{2} k_{\theta} \theta^{2}
$$

where $k_{h}$ is bending stiffness coefficient and $k_{\theta}$ is torsional stiffness coefficient.

Based on (1) (2) and using Lagrange formulation,

$$
\frac{d}{d}\left(\frac{\partial(T-U)}{\partial \dot{q}_{i}}\right)-\frac{\partial(T-U)}{\partial q_{i}}=Q_{i}
$$

The discrete differential motion can be expressed as follows:

$$
\begin{array}{r}
m \ddot{h}+k_{h} h-k_{h} x_{e} \theta-F=0, \\
J \ddot{\theta}-k_{h} x_{e} h+k_{h} x_{e}^{2} \theta+k_{\theta} \theta-M_{y}=0 .
\end{array}
$$

Equation (4) can be also written as matrix form:

$$
\left[\begin{array}{cc}
m & 0 \\
0 & J
\end{array}\right]\left[\begin{array}{l}
\ddot{h} \\
\ddot{\theta}
\end{array}\right]+\left[\begin{array}{cc}
k_{h} & -k_{h} x_{e} \\
-k_{h} x_{e} & k_{h} x_{e}^{2}+k_{\theta}
\end{array}\right]\left[\begin{array}{l}
h \\
\theta
\end{array}\right]=\left[\begin{array}{c}
F \\
M_{y}
\end{array}\right] .
$$

\section{Optimizing the Mathematical Model of the Blade}

In order to improve the efficiency, reliability, and stability, the optimization and design method were critically needed according to aerodynamic and structural conditions. In this case, establishing mathematical model is a profound significant to design blade. In this study, the blade twist angle, chord length, and relative layer thickness are, respectively, defined as optimization design variables, and these variables determine the blade aerodynamic performance. The tip deformation and output power are used as a constraint. Finally, the minimum mass of flexible blade is considered as the optimized objective. As a result, the mathematic model of the optimal design process is defined by

$X$

$$
\begin{aligned}
& \quad=\left[x_{\beta 1}, x_{\beta 2}, \ldots, x_{\beta n}, x_{c 1}, x_{c 2}, \ldots, x_{c n}, x_{t 1}, x_{t 2}, \ldots, x_{t n}\right] \\
& P \geq C_{1} \\
& L \leq C_{2} \\
& F(x)_{\min }=m=\sum_{i} \rho_{i} V_{i}
\end{aligned}
$$

in which $x_{\beta i}(i=1,2,3, \ldots, n)$ is the twist angle of $i$ th cross section $\left({ }^{\circ}\right) ; x_{c i}(i=1,2,3, \ldots, n)$ is the chord length of $i$ th cross section $(\mathrm{m}) ; x_{t i}(i=1,2,3, \ldots, n)$ is the layer thickness of $i$ th cross section $(\mathrm{mm}) ; P$ is power $(\mathrm{Kw}) ; C_{1}$ and 
TABLE 1: The corresponding parameters of the wind turbine.

\begin{tabular}{lc}
\hline Rated power $/ \mathrm{kw}$ & 1500 \\
Rotor diameter/m & 83 \\
Rated speed $/ \mathrm{rpm}$ & 17.2 \\
Cut-in wind speed $/\left(\mathrm{m} \cdot \mathrm{s}^{-1}\right)$ & 3 \\
Cut-out wind speed $/\left(\mathrm{m} \cdot \mathrm{s}^{-1}\right)$ & 25 \\
Tip speed ratio & 8.5 \\
\hline
\end{tabular}

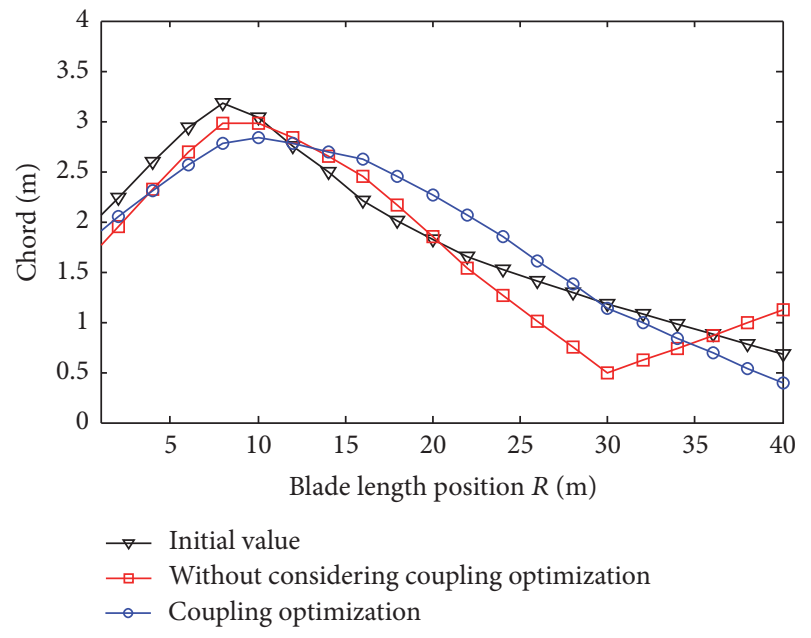

FIGURE 2: Comparison of chord optimization curve.

$C_{2}$ are given constant; $L$ is the tip deformation $(\mathrm{m}) ; m$ is blade mass $(\mathrm{kg}) ; \rho_{i}$ is the $i$ th material density; $V_{i}$ is the $i$ th material volume.

\section{Results and Discussion}

4.1. Airfoil Data. The four airfoils of S809-32, S808-25, S825-24, and S825-21 were selected, where the results were obtained using the aerodynamics characteristics. The four airfoils are more popular symmetrical airfoils; meantime, the experimental data of these airfoils are public; as a result, there are more experimental data available in the literature. The corresponding parameters of wind turbine are listed in Table 1.

4.2. Optimizing Calculation. The blade chord length, twist angle, and ply thickness are regarded as the optimization design variables; the blade mass is used as optimization objective [11]. Figure 2 shows the curve of the blade chord length before and after coupling optimization under aerodynamic and structural conditions.

The overall chord lengths tend to decrease after optimization, but the reduction is smaller near the tip relative to the blade root. However, it can be also observed that the increase chord in the middle distribution along the spanwise direction. Considering tip and root factor in the calculating, the optimization process mainly consists of increasing chord of the tip and root of blade to compensate for their energy

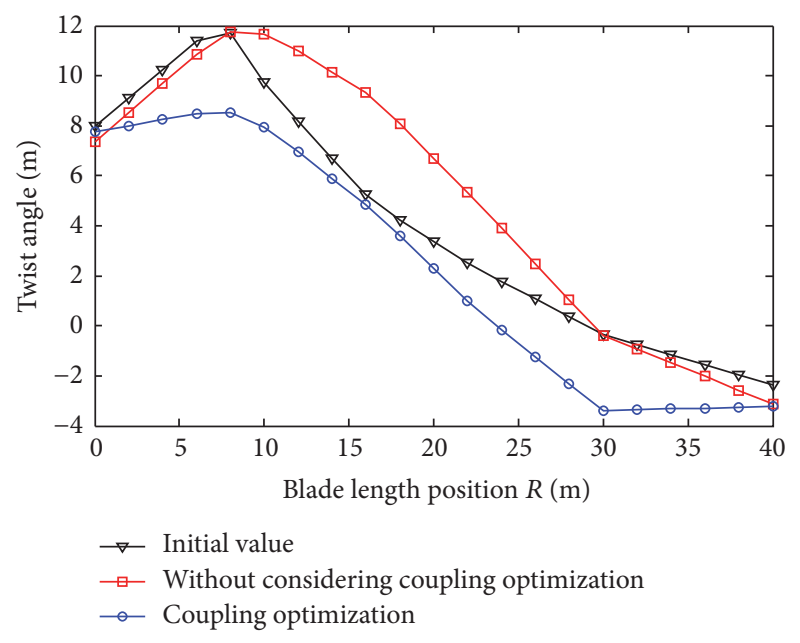

Figure 3: Comparison of twist optimization curves.

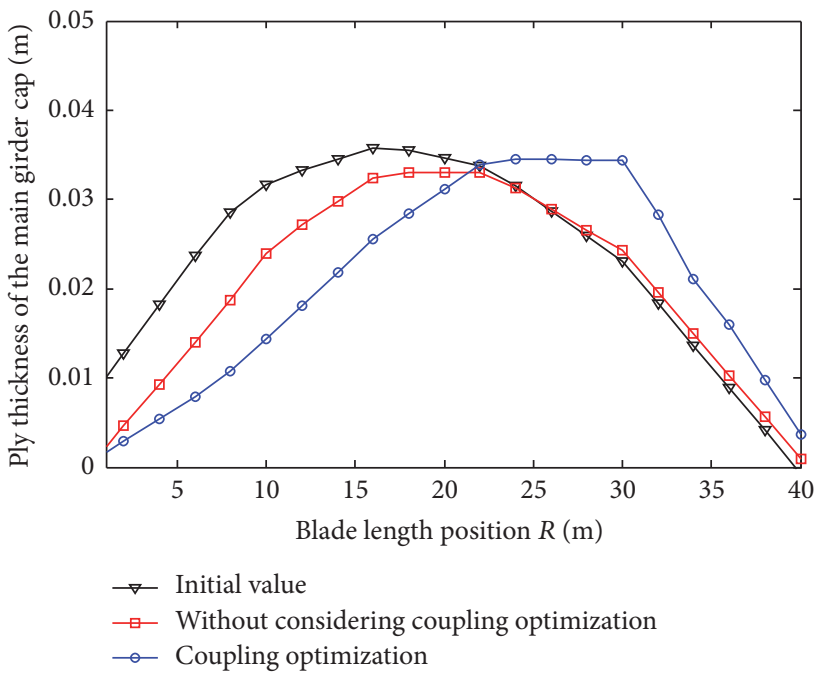

FIGURE 4: Comparison of thicknesses of beam optimization curves.

losses. In rigid case, such phenomenon is more prominent, which is consistent with the actual conditions. Figure 3 shows the curve of the blade twist angle before and after coupling optimization under aerodynamic and structural conditions.

It can be seen that the overall twist angle significantly increased after optimization with the rigid conditions from the curve of the blade twist angle after coupling optimization under aerodynamic and structural. Considering the influence of aerodynamic and structural interaction, the chord length value after optimization becomes smaller, while twist angle increase can contribute to the regional power. It indicated that the decrease chord can compensate for the energy losses. The twist angle decrease of the root of blade was also the main reason for the chord increase of the root.

As shown in Figure 4, the curve of the ply thickness of main girder has been changed before and after coupling optimization of aerodynamic and structural conditions. The ply 


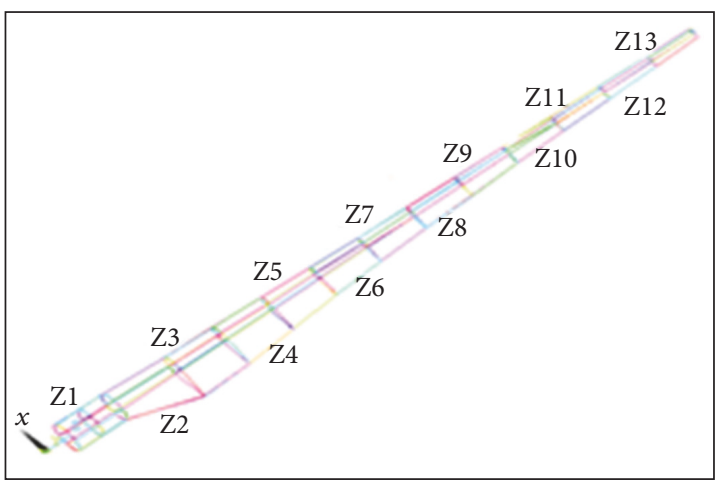

FIGURE 5: Blade partition along the span.

thickness of the main girder cap after optimization increased in the blade root and decreased in the blade tip under the rigid conditions, which repositioned the center of mass of the blade girder close to the blade root. However, considering the coupling influence conditions and the interaction between aerodynamic and structural conditions, the ply thickness distribution of the main girder cap is just the opposite, which repositions the mass center of the blade girder close to the blade tip.

\section{FE Model of Wind Turbine Blade}

5.1. FE Model. The FE model of the wind turbine blade with S809 airfoil was created in ANSYS software. The 8nodal shell of the SHELL 99 type with 6 degrees of freedom was chosen as finite elements. It is a parametric model, as the thickness of the shell, composite material, which blade is made, number of stiffening ribs, and their arrangement were the model parameters that were input from the authors' program that implemented a modified genetic algorithm. The FE model of the sample blade was built. The blade's layup methods are different in the aspects of the chord and spanwise direction. It was difficult in dividing the mesh basis for the actual structure areas. Implying assumption was made when creating the numerical model of the blade; blade can be simplified by being divided into 13 sections by each cross section of the airfoil along the direction of the development to the aerodynamic layout. The FE blade model is shown in Figure 5, which is division partition along the span.

Due to the structure design results, the top and bottom skins can be divided into 6 separate zones by using ply change position; specifically P6 is the web plate partition (see Figure 6).

5.2. Constraints. The blade was fixed to a hub by bolts as rigid connection, so the blade can be simplified as a cantilever beam structure. The whole constraint is adopted in the blade root. Both of mass and aerodynamic loads were investigated. The boundary constraint is illustrated in Figure 7.

The aim of this study was estimation of the influence of composite materials, with which the blade is made, on

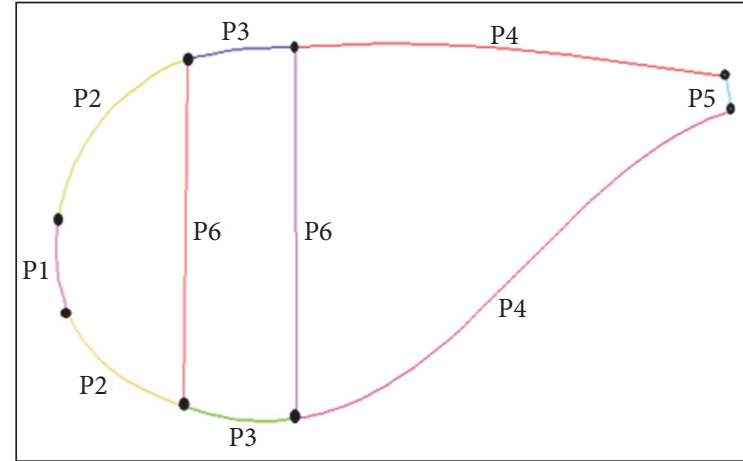

FIgURE 6: The division of blade along chord direction.

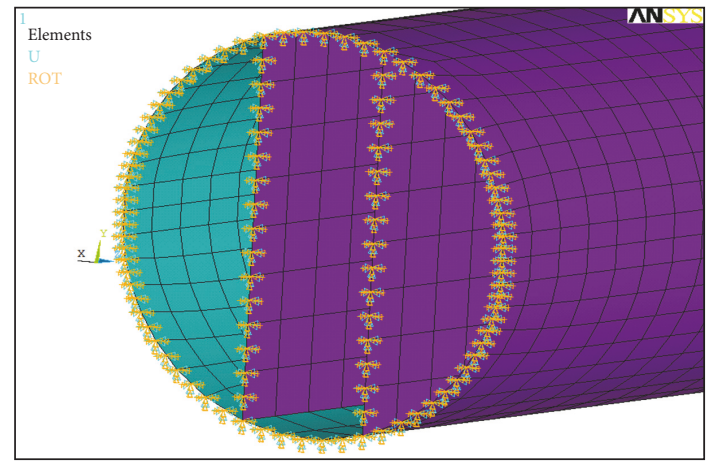

FIGURE 7: Boundary constraints.

TABLE 2: Layup thickness of partitions unit: $\mathrm{mm}$.

\begin{tabular}{lcccccc}
\hline \multirow{2}{*}{ Spanwise location } & \multicolumn{7}{c}{ Partition } \\
& P1 & P2 & P3 & P4 & P5 & P6 \\
\hline Z1 & 0.57 & 0.97 & 1.39 & 0.57 & 0.97 & 2.28 \\
Z2 & 0.57 & 0.97 & 1.39 & 0.57 & 0.97 & 4.55 \\
Z3 & 0.57 & 0.97 & 1.39 & 0.57 & 0.97 & 4.55 \\
Z4 & 0.57 & 0.97 & 1.39 & 0.57 & 0.97 & 3.42 \\
Z5 & 0.57 & 0.97 & 1.39 & 0.57 & 0.97 & 3.42 \\
Z6 & 0.57 & 0.97 & 1.39 & 0.57 & 0.97 & 3.42 \\
Z7 & 0.57 & 0.97 & 1.39 & 0.57 & 0.97 & 2.28 \\
Z8 & 0.57 & 0.97 & 1.39 & 0.57 & 0.97 & 2.28 \\
Z9 & 0.57 & 0.97 & 1.39 & 0.57 & 0.97 & 2.28 \\
Z10 & 0.57 & 0.97 & 1.39 & 0.57 & 0.97 & 2.28 \\
Z11 & 0.57 & 0.97 & 1.39 & 0.57 & 0.97 & 2.28 \\
Z12 & 0.57 & 0.97 & 1.39 & 0.57 & 0.97 & 2.28 \\
Z13 & 0.57 & 0.97 & 1.39 & 0.57 & 0.97 & 2.28 \\
\hline
\end{tabular}

dynamical properties of wind turbine blades. The mechanism relationship was investigated between the composite blade tip deformation and the load distribution. For the skin bearing structure with a one-way layer, the $45^{\circ}$ unidirectional layer material is $5: 1$ resin matrix composites, which has a density of $1550 \mathrm{~kg} / \mathrm{m}^{3}$ and Poisson's ratio of 0.26 . The layup thickness of all partitions along the span-wise are listed in Table 2. 


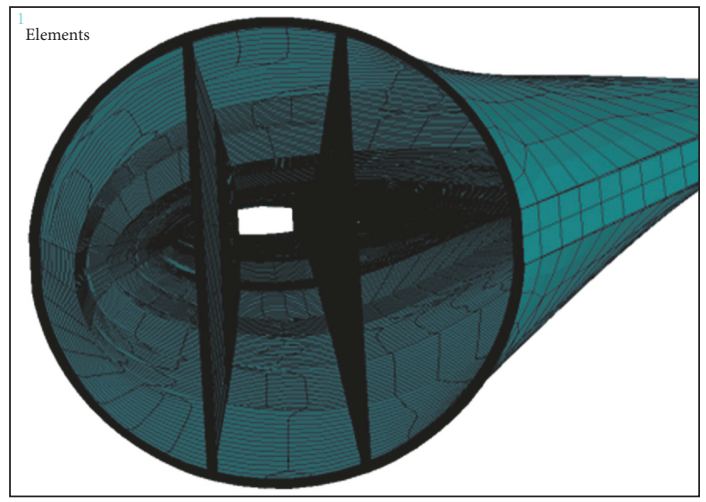

Figure 8: The finite element model.

TABLE 3: The first six natural frequencies unit: $\mathrm{Hz}$.

\begin{tabular}{lcc}
\hline Order & Optimized blade & Conventional blade \\
\hline 1st & 1.3254 & 1.61 \\
2nd & 2.7531 & 3.58 \\
3rd & 3.6507 & - \\
4th & 7.0956 & - \\
5th & 7.6972 & - \\
6th & 12.739 & - \\
\hline
\end{tabular}

The created FE model of the blade consists of 62042 elements, 26363 nodes, and 327 areas meshed. The first process was based on the ANSYS software SHELL99 elements conformed by $9038 \mathrm{DOF}$. Because of its large sizes, this model was able to reproduce the blade's geometry and layup very accurately. The element shape was adopted as a triangular mesh. The Block Lanczos method not only has higher speed and precision but also further handle the rigid vibration types, which is used to extract modal number of the blades. The FE model is presented in Figure 8.

5.3. Prestressed Modal Analysis. During analysis, the PSTRES switch of software was used, because the composite blade has a low rotational speed. Only extracting the first six frequencies of vibration was needed. The natural frequencies behavior of the blade is analyzed comprehensively and calculated when the rotational speed is $0 \mathrm{~m} / \mathrm{s}$, taking full constraint load mode on the blade root. In other words, all nodes of the blade root are fully fixed, so the blade is regarded as a cantilever beam model. The first two natural frequencies of the optimized blade and a conventional blade are listed in Table 3.

Table 3 shows the variation of the first and second natural frequencies of optimized blade, which is lower than that of the commercial blade, because the commercial blade is subjected to the influence of specific external airflow. Furthermore, with the aerodynamic and structure coupling conditions, the airflow density going through the blade and the mass of blade is increased, causing the natural frequency of blade to significantly decrease. It is fully illustrated that the interaction with aerodynamic and structural conditions cannot be neglected. The first six modes shapes of the blade are presented in Figure 9.

Figure 9 shows that the modes of the blade are mostly flapwise vibration. The first four modes of the blade are all for flapwise mode of vibration. Due to the twist of spars, the blade will not clearly vibrate with edgewise or flapwise. However, the blades begin to appear edgewise and flapwise, and the first order has mixed modes with flapwise and torsional. The rated rotational speed is $v=10 \mathrm{~m} / \mathrm{s}$; the tip speed of blade is $v=85 \mathrm{~m} / \mathrm{s}$. The excitation frequency of the rotating blade, namely, the first-order flapwise frequency, is $1.3254 \mathrm{~Hz}$ (when rotational speed is $79.524 \mathrm{rpm})$. Obviously, the rotational speed $(79.524 \mathrm{rpm})$ is far more than the operation speed $(12.18 \sim 17.2 \mathrm{rpm})$. Therefore, the blades appear at the start during normal working.

\section{Conclusions}

(1) The proposed mathematical model represents a simple alternative tool for the optimal design of the wind blade, especially for turbines with multi bladed rotors, where the proposed optimization can improve the efficiency. Compared to the natural frequency of the commercial blade, a mathematical optimization model is proposed to describe the cross section of the blade in the interaction between aerodynamic and structural conditions. In particular, the minimum mass of blade is used as the optimization objective and the tip deformation and output power are used as constraint condition. It is shown that the overall performance of the blade is gradually enhanced by optimization calculation.

(2) The modes of the blade consist of flapwise, edgewise, and torsional; the frequencies of flapwise and edgewise were lower than that of torsional.

(3) Compared to the natural frequency of a commercial blade, in the aerodynamic and structural coupling effect conditions, the interaction mechanism relationship between blade deformation and the load distribution was analyzed. The optimized blade does not exhibit resonant behavior. 


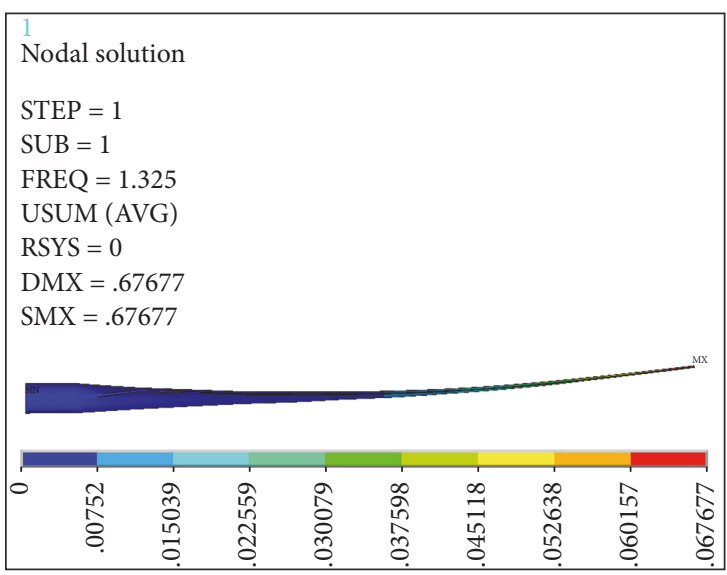

(a) The 1st mode of the blade

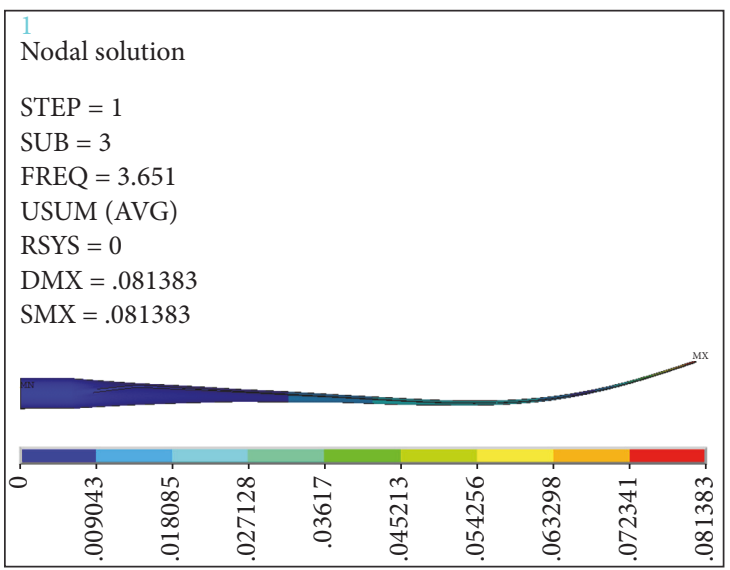

(c) The 3th mode of the blade

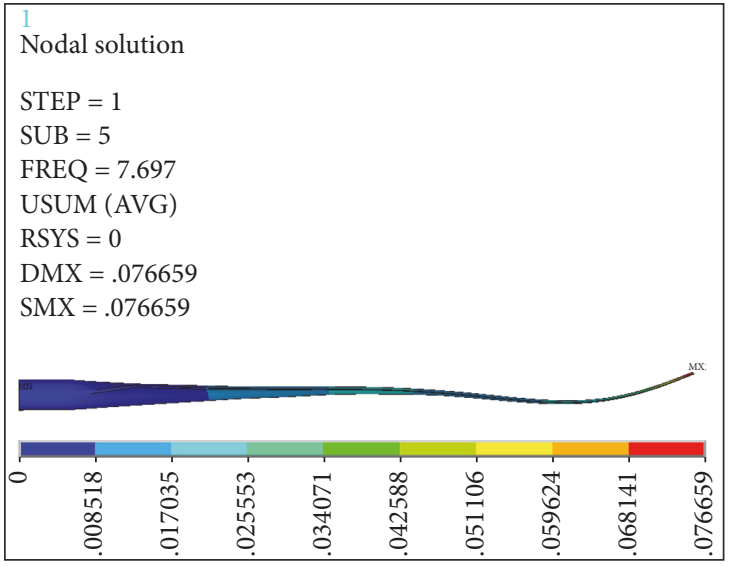

(e) The 5th mode of the blade

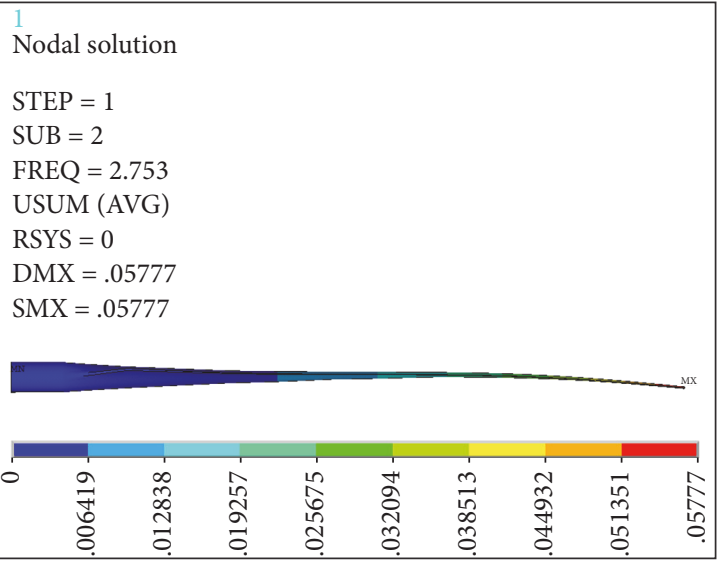

(b) The 2nd mode of the blade

Nodal solution

STEP $=1$

$\mathrm{SUB}=4$

FREQ $=7.096$

USUM (AVG)

RSYS $=0$

$\mathrm{DMX}=.08732$

$\mathrm{SMX}=.08732$

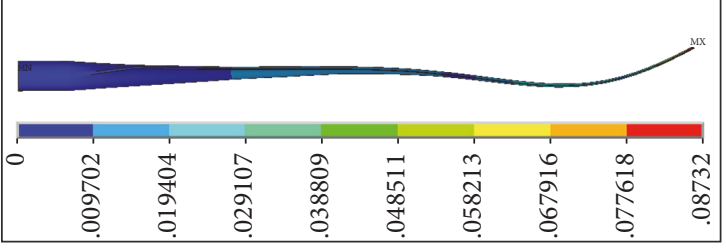

(d) The 4th mode of the blade

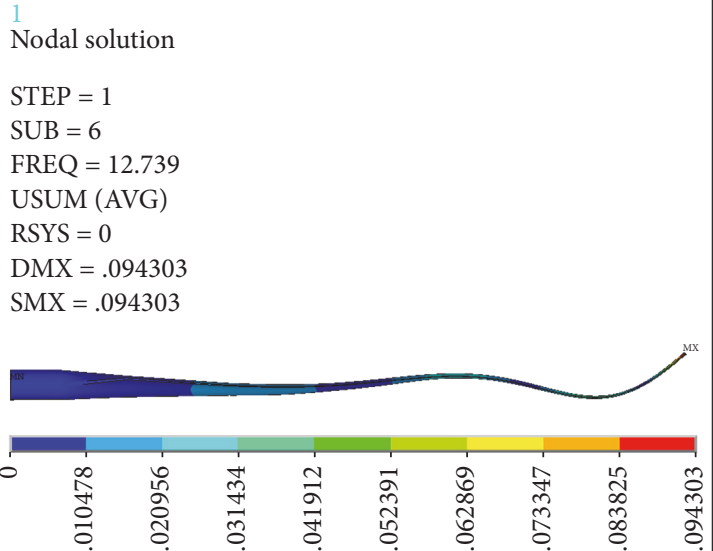

(f) The 6th mode of the blade

Figure 9: The first six modes of the blade.

\section{Conflicts of Interest}

The authors declare that they have no conflicts of interest.

\section{Acknowledgments}

The authors would like to acknowledge the support provided by the National Natural Science Foundation of China (Grant no. 51565028).

\section{References}

[1] Y. Zheng, R. Zhao, and H. Liu, "Research of aerodynamic and structural coupling optimization design for blade of large-scale wind turbine," Taiyangneng Xuebao/Acta Energiae Solaris Sinica, vol. 36, no. 8, pp. 1812-1817, 2015.

[2] T. R. Liu and Y. S. Ren, "Vibration and flutter of wind turbine blade modeled as anisotropic thin-walled closed-section beam," Science China Technological Sciences, vol. 54, no. 3, pp. 715-722, 2011. 
[3] D. Hu, Z. Zhichao, and Z. Jianping, "Modal analysis of wind turbine blade based on fluid-structure interaction," Renewable Energy Resources, vol. 32, pp. 1168-1174, 2014.

[4] J. Yin, W. Liu, and P. Chen, "Modal re-analysis of rotary wind turbine blades in refinement design," Wind Energy, vol. 15, no. 6, pp. 864-881, 2012.

[5] D. Cárdenas, A. A. Escárpita, H. Elizalde et al., "Numerical validation of a finite element thin-walled beam model of a composite wind turbine blade," Wind Energy, vol. 15, no. 2, pp. 203-223, 2012.

[6] M. Harte, B. Basu, and S. R. K. Nielsen, "Dynamic analysis of wind turbines including soil-structure interaction," Engineering Structures, vol. 45, pp. 509-518, 2012.

[7] B.-Y. Kang, J.-Y. Han, C.-H. Hong, and B.-Y. Moon, "Dynamic analysis of hybrid wind power composite blades according to stacking properties method," International Journal of Precision Engineering and Manufacturing, vol. 13, no. 7, pp. 1161-1166, 2012.

[8] V. H. Cortínez and M. T. Piovan, "Vibration and buckling of composite thin-walled beams with shear deformability," Journal of Sound and Vibration, vol. 258, no. 4, pp. 701-723, 2002.

[9] M. M. Shokrieh and R. Rafiee, "Simulation of fatigue failure in a full composite wind turbine blade," Composite Structures, vol. 74, no. 3, pp. 332-342, 2006.

[10] D. J. Malcolm and D. L. Laird, "Extraction of equivalent beam properties from blade models," Wind Energy, vol. 10, no. 2, pp. 135-157, 2007.

[11] Y. Zheng, R. Zhao, and H. Liu, "Optimization method for girder of wind turbine blade," Mathematical Problems in Engineering, vol. 2014, Article ID 898736, pp. 7-9, 2014. 


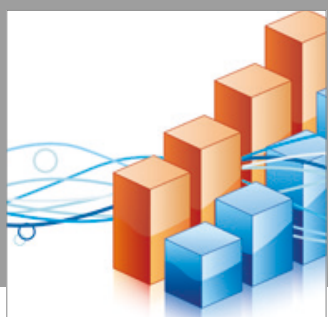

Advances in

Operations Research

vatersals

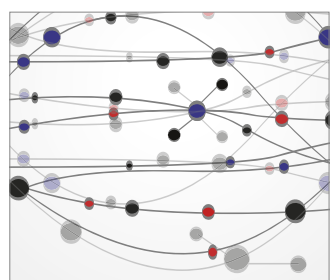

\section{The Scientific} World Journal
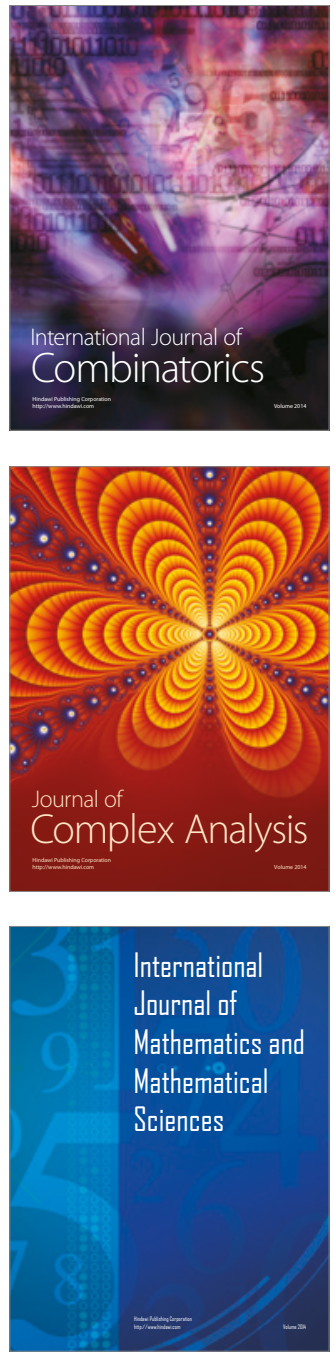
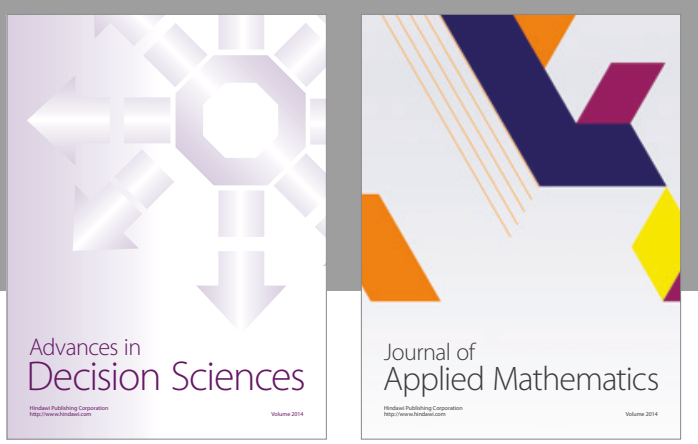

Algebra

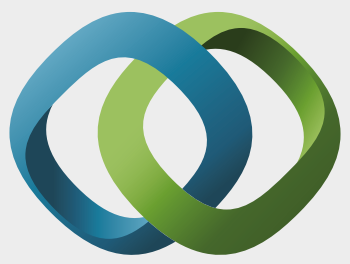

\section{Hindawi}

Submit your manuscripts at

https://www.hindawi.com
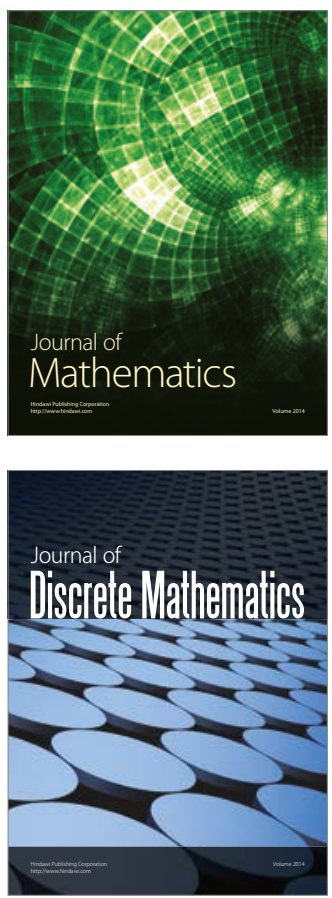

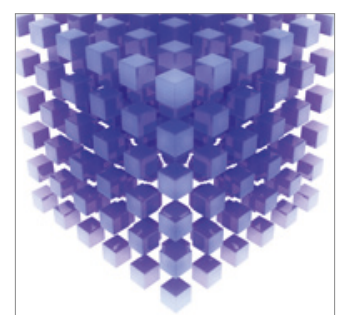

Mathematical Problems in Engineering
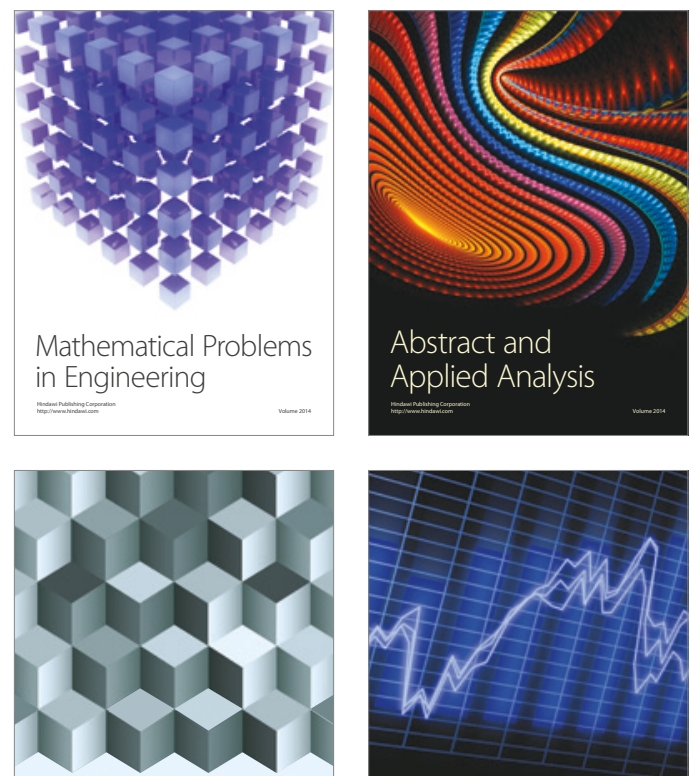

Journal of

Function Spaces

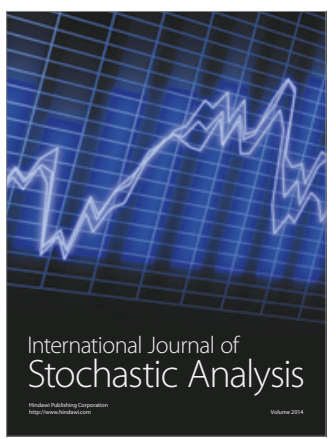

Probability and Statistics
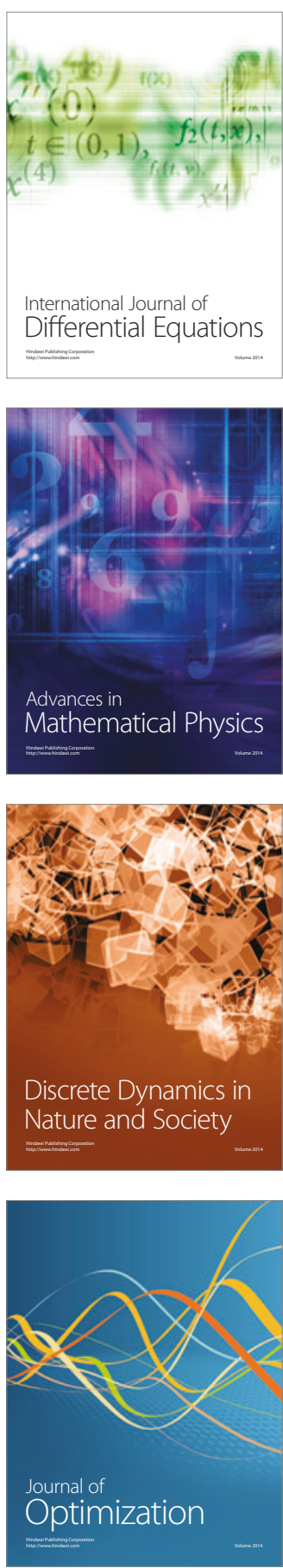